\title{
Detection of 3D Cardiac metabolism after injection of hyperpolarized [1-13C]pyruvate
}

\author{
Francesca Frijia ${ }^{*}$, Florian Wiesinger ${ }^{2}$, Maria Filomena Santarelli ${ }^{3}$, Vincenzo Positano ${ }^{1}$, Jan Henrik Ardenkjaer-Larsen ${ }^{4}$, \\ Rolf Schulte ${ }^{2}$, Luca Menichetti ${ }^{3}$, Giulio Giovannetti ${ }^{3}$, Giacomo Bianchi ${ }^{5}$, Giovanni Aquaro ${ }^{1}$, Vincenzo Lionetti ${ }^{5}$, \\ Daniele De Marchi ${ }^{1}$, Alessandra Flori ${ }^{6}$, Luigi Landini ${ }^{1}$, Fabio Anastasio Recchia ${ }^{5}$, Massimo Lombardi ${ }^{1}$
}

From 2011 SCMR/Euro CMR Joint Scientific Sessions

Nice, France. 3-6 February 2011

\section{Introduction}

MRI with hyperpolarised ${ }^{13} \mathrm{C}$ represents a promising modality for in-vivo spectroscopy and provides a unique opportunity for non-invasive assessment of cardiac regional metabolism.

\section{Purpose}

We present a method based on a volumetric IDEAL spiral CSI acquisition for obtaining spatial information on the metabolism of the whole heart after intravenous injection of hyperpolarized [1-13C]pyruvate in a large animal model with a clinical 3T scanner.

\section{Methods}

Three healthy male mini-pigs $(38 \pm 2 \mathrm{~kg})$ were maintained under deep sedation; a dose of $20 \mathrm{~mL}$ of $230 \mathrm{mM}$ [1-13C]pyruvate was administered over about $10 \mathrm{~s}$ by manual injection. Animal experiments were performed on a 3T GE Signa HDx scanner with a $13 \mathrm{C}$ quadrature birdcage coil.

[1-13C]pyruvate was polarized using a HyperSense DNP polariser with subsequent dissolution. The final injection solution contained $230 \mathrm{mM}$ sodium [1-13C] pyruvate, $100 \mathrm{mM}$ TRIS buffer, $0.27 \mathrm{mM} \mathrm{Na}_{2}$ EDTA and $20 \mu \mathrm{M}$ Dotarem with $\mathrm{T} \approx 37^{\circ} \mathrm{C}$ and $\mathrm{pH} \approx 7.6$.

Anatomical reference images were acquired in the axial plane with standard FIESTA sequence (body coil $\mathrm{FOV}=30 \times 30 \mathrm{~cm}^{2}, \mathrm{FA}=20^{\circ}, \mathrm{TE} / \mathrm{TR}=3.8 \mathrm{~ms} / 7.52 \mathrm{~ms}$, matrix $224 \times 160$, slice thickness $5 \mathrm{~mm}$, 20 slices).

Metabolic information covering the heart were obtained using a 3D IDEAL spiral CSI prescribed on the same region imaged by the reference anatomical sequence $(\mathrm{FOV}=30 \times 30 \mathrm{~cm}$, slab thickness $=100 \mathrm{~mm})$ starting 20 seconds after the beginning of the hyperpolarized $\left[1^{13} \mathrm{C}\right]$-pyruvate injection. The IDEAL spiral CSI concept was implemented into a multi-slice, pulse-and-acquire sequence with a $2 \mathrm{D}$ spiral readout and phase encoding along the third dimension. A constant echo time shift of $\mathrm{TE}=0.9 \mathrm{~ms}, 11$ encoding steps and $\mathrm{FA}=7^{\circ}$ were used to optimize the study for the considered frequencies.

The data was reconstructed using spectrally-preconditioned, minimum-norm CS inversion followed by gridding reconstruction implemented in Matlab. The reconstruction on cardiac short axis (SA) and image fusion was performed by PMOD software.

\section{Results}

Pyruvate and its metabolic products lactate and bicarbonate were detected in the heart. Metabolic maps overlaid on anatomical images are shown in Figure 1. On SA sections the metabolites signal resulted correctly localized in cardiac structures: pyruvate more evident in ventricular cavity, bicarbonate in myocardial wall.

\section{Conclusions}

This study demonstrated that the volumetric spatial localization of ${ }^{13} \mathrm{C}$ metabolites on the whole pig heart can be acquired with a 3D IDEAL spiral CSI sequence. This allows investigation of the metabolic behaviour over all the heart, both in normal and pathological conditions.

${ }^{1}$ Fondazione G.Monasterio CNR-Regione Toscana, Pisa, Italy

Full list of author information is available at the end of the article

(c) 2011 Frijia et al; licensee BioMed Central Ltd. This is an open access article distributed under the terms of the Creative Commons Attribution License (http://creativecommons.org/licenses/by/2.0), which permits unrestricted use, distribution, and reproduction in any medium, provided the original work is properly cited. 


\section{Author details}

${ }^{1}$ Fondazione G.Monasterio CNR-Regione Toscana, Pisa, Italy. ${ }^{2} \mathrm{GE}$ Global

Research, Munich, Germany. ${ }^{3}$ Institute of Clinical Physiology, National Research Council, Pisa, Italy. ${ }^{4}$ GE Healthcare, Huginsvej, 3400 Hillerod,

Denmark. ${ }^{5}$ Sector of Medicine, Scuola Superiore Sant'Anna, Pisa, Italy. ${ }^{6}$ Scuola

Superiore Sant'Anna, Pisa, Italy.

Published: 2 February 2011

doi:10.1186/1532-429X-13-S1-M2

Cite this article as: Frijia et al:: Detection of 3D Cardiac metabolism after injection of hyperpolarized [1-13C]pyruvate. Journal of Cardiovascular

Magnetic Resonance 2011 13(Suppl 1):M2.

Submit your next manuscript to BioMed Central and take full advantage of:

- Convenient online submission

- Thorough peer review

- No space constraints or color figure charges

- Immediate publication on acceptance

- Inclusion in PubMed, CAS, Scopus and Google Scholar

- Research which is freely available for redistribution

Submit your manuscript at www.biomedcentral.com/submit
C Biomed Central 